\title{
ПРОГРАМНИЙ КОМПЛЕКС ДЛЯ ОБРОБКИ СИНХРОННО ЗАРЕЄСТРОВАНИХ БІОСИГНАЛІВ У ПОЛІГРАФАХ
}

\author{
А. С. Сверстюк, Н. О. Кравець, В. П. Касянюк \\ ДВНЗ «Тернопільський державний медичний університет \\ імені І. Я. Горбачевського МОЗ України»
}

У роботі описано розробку програмного комплексу, який дає змогу проводити сумісну статистичну обробку синхронно зареєстрованих біосигналів в поліграфах на основі моделі вектора циклічних ритмічно пов'язаних випадкових процесів.

Ключові слова: синхронно зареєстровані біосигнали, методи статистичної обробки, програмний комплекс.

\section{ПРОГРАММНЫЙ КОМПЛЕКС ДЛЯ ОБРАБОТКИ СИНХРОННО ЗАРЕГИСТРИРОВАННЫХ БИОСИГНАЛОВ В ПОЛИГРАФАХ}

\author{
А. С. Сверстюк, Н. О. Кравец, В. П. Касянюк \\ гВУз «Тернопольский государственный медицинский университет \\ имени И. Я. Горбачевского МЗ Украины»

\begin{abstract}
В работе описана разработка программного комплекса, который позволяет проводить совместную статистическую обработку синхронно зарегистрированных биосигналов в полиграфах на основе модели вектора циклических ритмично связанных случайных процессов.
\end{abstract}

Ключевые слова: синхронно зарегистрированные биосигналы, методы статистической обработки, программный комплекс.

\section{PROGRAM COMPLEX FOR TREATMENT OF REGISTERED SYNCHRONOUS BIOSIGNALS IN POLYGRAPH}

\author{
A. S. Sverstyuk, N. O. Kravets, V. P. Kasyanyuk \\ SHEI «Ternopii State Medical University by I.Ya.Horbachevsky of MPH of Ukraine»
}

The work described a software package, which provides the compatible statistical processing simultaneously registered in the polygraph biosignals based on a model vector cyclical rhythm associated random processes.

Key words: synchronously recorded biosignals, methods of statistical processing software package.

Вступ. Функціонування організму людини як біофізичної системи супроводжується генеруванням електричних, магнітних, механічних полів, змінами дихання, тиску, шкірно-гальванічної реакції, оптичної густини тканин, що у просторово-часовій структурі відображають функціональний стан психофізіологічної системи людини і дають змогу проводити іiі діагностику та тестування.

Коли людина говорить неправду, змінюються характеристики біосигналів, внаслідок неузгодженості реальної дійсності та модульованої неправдивої інформації, на цьому факті грунтується ідея обстеження на поліграфі.
Поліграф є комплексом, що складається з давачів, сенсорного блоку, комп'ютера та сучасного програмного забезпечення, яким керує фахівець-поліграфолог. Поліграф забезпечує прийом біосигналів від давачів по 7-12 незалежних каналах, що дає змогу реєструвати фотоплетизмограму, шкірно-гальванічну реакцію, верхнє та нижнє дихання, зміни кров'яного тиску, мовний сигнал, автоматичне оцінювання загальної напруженості обстежуваного, психологічну складову в реальному масштабі часу [1] .

Повну інформацію при обстеженні на поліграфі можна отримати лише за умови паралельного використання декількох методів автоматизованої діагно- 
стики на базі ЕОМ, а отримані дані повинні розглядатися $з$ єдиної точки зору. Такий підхід дозволяє певним чином уніфікувати автоматизовану обробку та моделювання різних за фізичною природою біосигналів та підвищити достовірність, повноту діагностики обстеження на поліграфі, внаслідок використання однотипних діагностичних ознак для різних класів досліджуваних сигналів.

Більшість існуючих методів обробки біосигналів Грунтуються на математичних моделях у вигляді вектора випадкових величин, стаціонарного випадкового процесу та стохастичного періодичного процесу. Однак, у цих математичних моделях не враховуються важливі властивості досліджуваних біосигналів - мінливість та спільність їх ритму.

Наведені вище аргументи вказують на актуальність розробки нової математичної моделі, методів сумісної статистичної обробки та імітації біосигналів на основі теорії випадкових процесів та випадкових полів, для потреб комплексного комп'ютерного обстеження на поліграфі.

Постановка завдання. Ефективність сучасних поліграфів значною мірою залежить від апаратної та програмної складових, на базі яких вони будуються. Використання різноманітних методів обробки, які закладаються в програмному забезпеченні, значно розширює функціональні можливості та підвищує достовірність обстеження на поліграфі [1]. В свою чергу, методи базуються на математичних моделях, які і задають можливості та специфіку обробки. Зокрема, сумісну обробку біосигналів можливо проводити лише за умови, що їх математичні моделі пев- ним чином узгоджені між собою і мають подібну структуру.

Робота багатьох сучасних кардіодіагностичних комплексів базується здебільшого на аналізі окремо кожного із синхронно зареєстрованих біосигналів (СЗБС). В якості прикладів розглядали поліграфи («Кріс», «Риф», «Арсенал», «LX4000-SW»). Слід зазначити, що у наведених поліграфах та багатьох працях [2-3] не враховується спільність ритму досліджуваних СЗБС.

У розробленому програмному комплексі використано підходи до сумісної статистичної обробки та моделювання СЗБС $з$ використанням моделей та методів теорії циклічних функціональних відношень, які описані в працях [4-6].

Основна частина. У працях $[4,5]$ описана математична модель СЗБС на основі вектора циклічних ритмічно пов'язаних випадкових процесів.

Згідно з роботою [4], дамо означення вектора циклічних ритмічно пов'язаних випадкових процесів.

Означення 1. Вектор $\Theta_{N}(\omega, t)$ циклічних випадкових процесів $\left\{\xi_{i}(\omega, t), i=1, N, \omega \in \Pi, t \in \mathrm{W}\right\}$ будемо називати вектором строго ритмічно пов'язаних випадкових процесів, а самі процеси строго ритмічно пов'язаними, якщо існує така функція Tit, n), яка задовольняє умовам функції ритму, що скінченновимірні вектори

$$
\left\{\xi_{i_{1}}\left(\omega, t_{1}\right), \xi_{i_{2}}\left(\omega, t_{2}\right), \ldots, \xi_{i_{k}}\left(\omega, t_{k}\right)\right\} \text { та }
$$

$$
\left\{\xi_{1_{1}}\left(\omega, t_{1}+T\left(t_{1}, n\right)\right), \xi_{i_{2}}\left(\omega, t_{2}+T\left(t_{2}, n\right)\right), \ldots, \xi_{i_{k}}\left(\omega, t_{k}+T\left(t_{k}, n\right)\right)\right\}
$$

$n \in \mathbf{Z}, i_{1}, \ldots, i_{k}=1, N$, де $\left\{t_{1}, \ldots, t_{k}\right\}$ - множина сепарабельності вектора $\Theta_{N}(\omega, t)$ при всіх цілих $k \geq 1$ є стохастнчно еквівалентними у широкому розумінні.

Областю визначення W вектора циклічних ритмічно пов'язаних випадкових процесів може бути або впорядкована дискретна

$$
\mathbf{W}=\mathbf{D}=\left\{t_{m l} \in \mathbf{R}, m \in \mathbf{Z}, l=\overline{1, L}\right\} \text {, або непе- }
$$

рервна $\mathrm{W}=\mathrm{R}$ множина дійсних чисел. У випадку дискретності області визначення $\mathrm{W}=\mathrm{D}$ для їі елементів має місце такий тип лінійного упорядкування: $t_{m_{1} l_{1}}<t_{m_{2} l_{2}}$,яюцо $m_{2}>m_{1}$, або якщо $m_{2}=m_{1}$, а $l_{2}>l_{1}$, в інших випадках $t_{m_{1} l_{1}}>t_{m_{2} l_{2}}, m_{1}, m_{2} \in \mathbf{Z}, l_{1}, l_{2} \in \overline{1, L}$. Причому $0<t_{m, l+1}-t_{m, l}<\infty$.

Функція ритму $T i i, n$ ) визначає закон зміни часових інтервалів між однофазними значеннями вектора циклічних ритмічно пов'язаних випадкових процесів. Функція ритму задовільняє таким умовам:

a) $\mathrm{T}(\mathrm{t}, \Pi)>0$, якщо п>0 $(T(t, 1)<\infty)$;

b) $\mathrm{T}(\mathrm{t}, \Pi)=0$, якщо п=0;

c) $\mathrm{T}(\mathrm{t}$, п) $<0$, якщо $\mathrm{n}<0, t \in \mathrm{W}$;

для будь-яких $t_{1} \in \mathrm{W}$ та $t_{2} \in \mathrm{W}$, для яких $t_{1}<t_{2}$, для функції $\mathrm{T}(\mathrm{t}$, п) виконується строга нерівність:

$$
T\left(t_{1}, n\right)+t_{1}<T\left(t_{2}, n\right)+t_{2}, \forall n \in \mathrm{Z}
$$


функція $\mathrm{T}(\mathrm{t}$, п) $є$ найменшою за модулем $\left(|T(t, n)| \leq\left|T_{\gamma}(t, n)\right|\right)$ серед усіх таких функцій $\left\{T_{\gamma}(t, n), \gamma \in \Gamma\right\}$, які задовольняють (1) та (2).

У частинному випадку, якщо функція ритму $T(t, n)=n \cdot T(T>0, n \in Z)$, то вектор $\Theta_{N}(\omega, t)$ будемо називати вектором Г періодично пов'язаних випадкових процесів.

Розглянемо властивості деяких ймовірнісних характеристик вектора $\Theta_{N}(\omega, t)$ циклічних ритмічно пов'язаних випадкових процесів. Так, для його сумісної k-вимірної функції розподілу має місце рівність

$$
\begin{gathered}
t_{k_{\xi_{k}} \zeta_{k}}\left(x_{1} 0 \ldots 0 x_{k} ; t_{1} 0 \ldots 0 x_{k}\right)= \\
=t_{k_{\xi_{1}} \xi_{\xi_{k}}}\left(x_{1} 0 \ldots 0 x_{k} ; t_{1}+T\left(t_{1} 0 n\right) 0 \ldots 0 x_{k}+T\left(t_{k} 0 n\right)\right) 0 n \in \mathbf{Z} 0 i_{1} 0 \ldots 0 i_{k}=10 N 0 t_{1} 0 \ldots 0 x_{k} \in \mathbf{W} .
\end{gathered}
$$

Змішана центральна моментна функція порядку

$p=\sum_{j=1}^{k} R_{j}:$

$$
\begin{aligned}
& r_{p_{\xi_{\eta_{1}} \xi_{t_{k}}}}\left(t_{1}, \ldots, t_{k}\right)=\mathbf{M}\left\{\left(\xi_{i_{1}}\left(\omega, t_{1}\right)-m_{\xi_{n}}\left(t_{1}\right)\right)^{R_{1}} \cdot \ldots \cdot\left(\xi_{i_{p}}\left(\omega, t_{k}\right)-m_{\xi_{k_{k}}}\left(t_{k}\right)\right)^{R_{k}}\right\}= \\
& =r_{p_{\xi_{1}} \xi_{k_{k}}}\left(t_{1}+T\left(t_{1}, n\right), \ldots, t_{k}+T\left(t_{k}, n\right)\right), t_{1}, t_{2}, \ldots, t_{k} \in \mathbf{W}, i_{1}, \ldots, i_{k}=1, N, n \in \mathbf{Z} .
\end{aligned}
$$

В роботах $[4,6,7]$ обгрунтовано методи інтерполяції, передискретизації біосигналів та функції ритму. Враховуючи результати попередніх досліджень
[8] розроблено програмний комплекс, що дає змогу проводити статистичну обробку СЗБС, структурна схема якого наведена на рисунку 1.

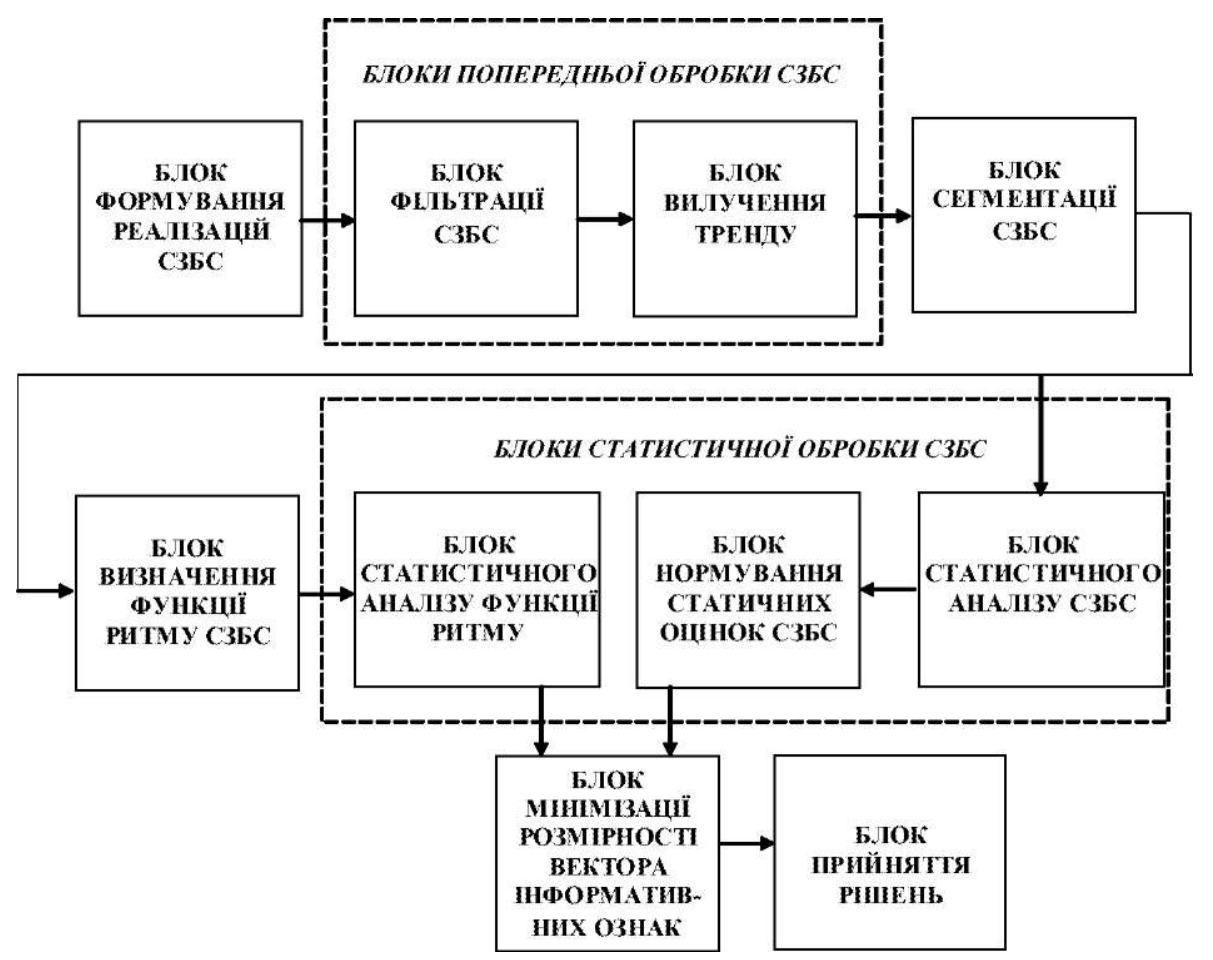

Puc. 1. Структурна схема програмного комплексу для статистичної обробки СЗБС. 
У блоці формування реалізацій СЗБС використовувалися експортовані синхронно зареєстровані їх значення з поліграфа "Арсенал". Блоки попередньої обробки призначені для фільтрації та вилучення тренду із СЗБС. Блок сегментації використовується для отримання зонно-часової структури СЗБС з метою визначення їх функцій ритму. Блоки статистичної обробки призначені для нормування статистичних оцінок, аналізу функції ритму та досліджуваних біосигналів. Блок мінімізації розмірності вектора інформативних ознак необхідний для мінімізації їх кількості, що репрезентує норму або певну патологію ССС. Блок прийняття рішень дає змогу підвищити точність та достовірність обстеження на поліграфі по СЗБС.
Особлива увага в даному програмному комплексі була зосереджена на розробці блоку статистичного аналізу СЗБС, який розглянемо детальніше. Програмне забезпечення для даного блоку написане мовою програмування Delphi 7 з використанням стандартних компонентів.

Блок статистичного аналізу СЗБС складається 3 двох модулів:

1. Модуль «Статистичної обробки біосигналів 3 врахуванням функції ритму та періоду».

2. Модуль «Сумісної статистичної обробки СЗБС».

Структурно-функціональна схема модуля «Статистична обробка біосигналів з врахуванням функції ритму та періоду» наведена на рисунку 2.

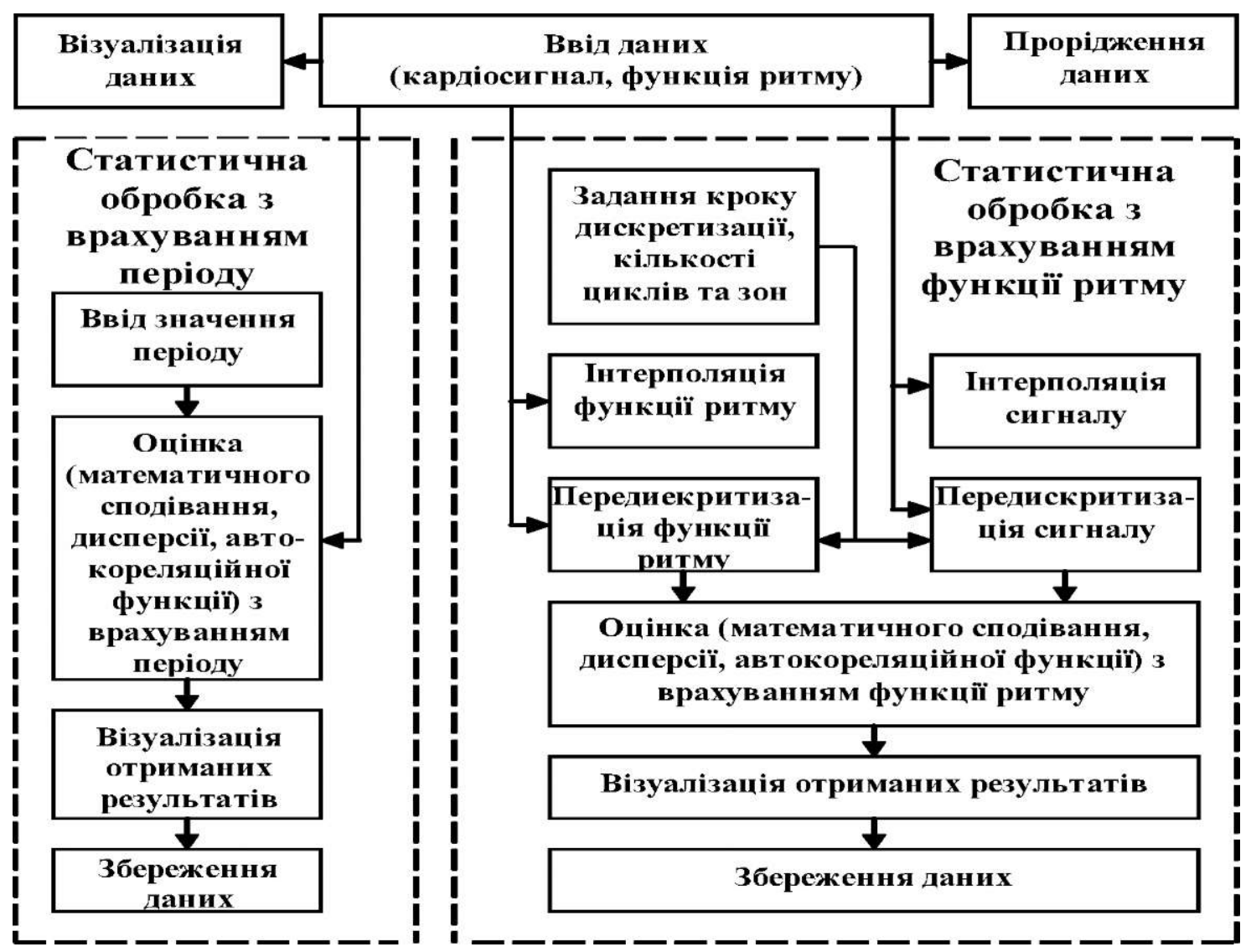

Puc. 2. Структурно-функціональна схема модуля програми «Статистична обробка біосигналів 3 врахуванням функції ритму та періоду».

Вказана схема працює наступним чином.

Спочатку вхідні дані кардіо сигналу та функції ритму відкриваються у форматі*.txt. Вхідними даними для програми є циклічні біо сигнали, які реєструє поліграф (фотоплетизмограма, верхнє та нижнє дихання, зміни кров'яного тиску), а також дискретна функція ритму. На рисунку $3(a, 6)$ поданий загальний вигляд інтерфейсів програми для вводу даних (біосигналів, функцій ритму) та їх візуалізації. 


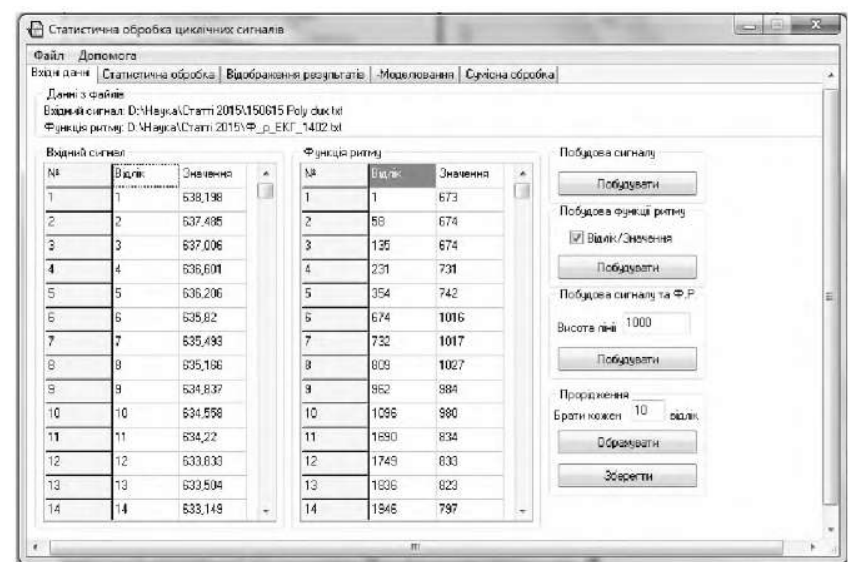

a

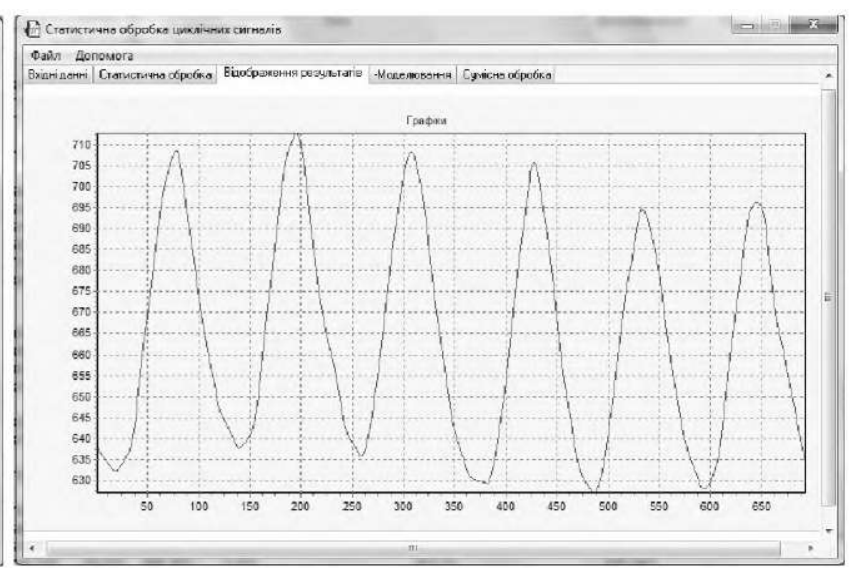

6

Puc. 3. Загальний вигляд інтерфейсів програми: а) для вводу даних (закладка «Вхідні дані»); б) для візуалізації даних (закладка «Відображення результатів»).

Для контролю вводу правильних даних на даному інтерфейсі програми передбачені кнопки для візуалізації введених даних «Побудова сигналу», «Побудова функції ритму». Крім цих можливостей програма дозволяє проводити прорідження сигналу 3 метою зменшення кількості відліків, що вплине на час обробки сигналів в цілому.

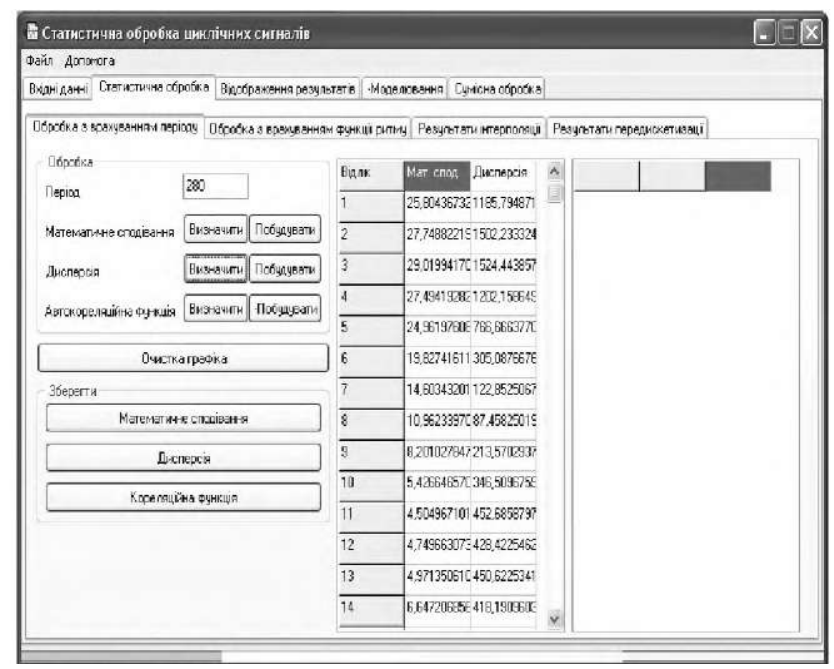

a
Для проведення статистичної обробки в програмі враховано два методи: метод усереднення значень реалізації сигналу з урахуванням періоду та метод усереднення значень реалізації сигналу з урахуванням функції ритму. Приклад інтерфейсу програми для проведення статистичної обробки з врахуванням періоду подано на рисунку 4.

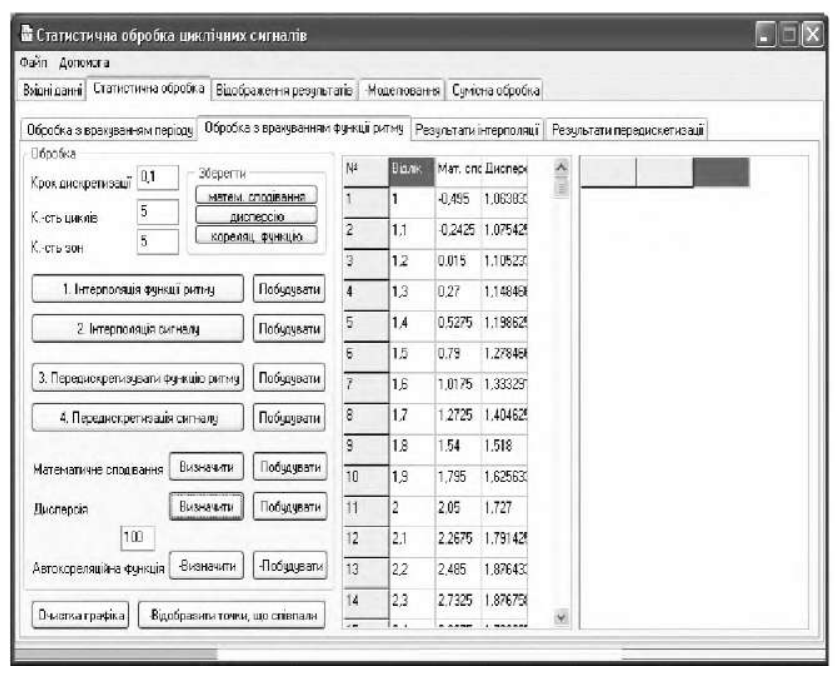

6

Puc. 4. Загальний вигляд інтерфейсів програми для проведення статистичної обробки: а) через період; б) з врахуванням функції ритму.

Під час проведення статистичної обробки з врахуванням періоду необхідно задати період біосигналу, а потім отримати оцінки імовірнісних характеристик (математичне сподівання, дисперсія та автокореляційна функція).

Під час проведення статистичної обробки з врахуванням функції ритму необхідно задати додаткові параметри, а саме: крок дискретизації сигналу i функції ритму (необхідний під час передискретизації сигналу та функції ритму), а також кількість циклів біосигналу та кількість зон (на циклі) зареєстрованої реалізації сигналу. Виконуючі послідовні кроки: інтерполяції функції ритму; інтерполяції сигналу; передискретизації функції ритму; передискретизації сигналу отримаємо необхідні дані для проведення статистичної обробки з врахуванням функції ритму.

3 рисунка 4 видно, що в результаті статистичної обробки ми можемо отримати оцінки таких імовір- 
нісних характеристик: математичне сподівання, дисперсія та автокореляційна функція. Усі отримані дані, при необхідності, можна зберегти в текстових файлах.
Для проведення сумісної статистичної обробки СЗБС використовується блок „Сумісна статистична обробка СЗБС", структурно-функціональна схема, якого наведена на рисунку 5.

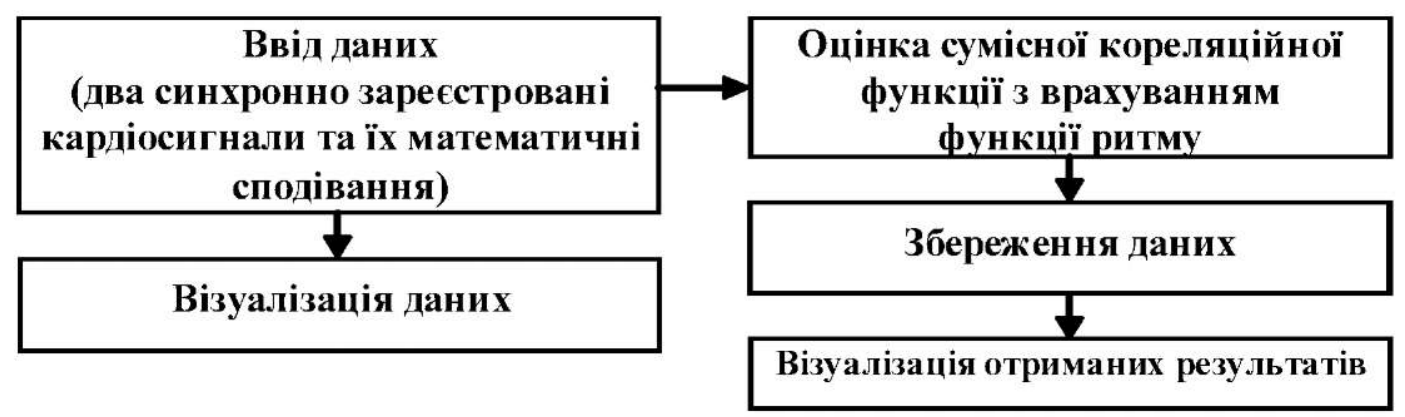

Puc. 5. Структурно-функціональна схема модуля програми «Сумісна статистична обробка СЗБС».

Вхідними даними для сумісної статистичної обробки є передискретизовані значення сигналів та отримані їх оцінки математичного сподівання. Результатом сумісної статистичної обробки є взаємно-

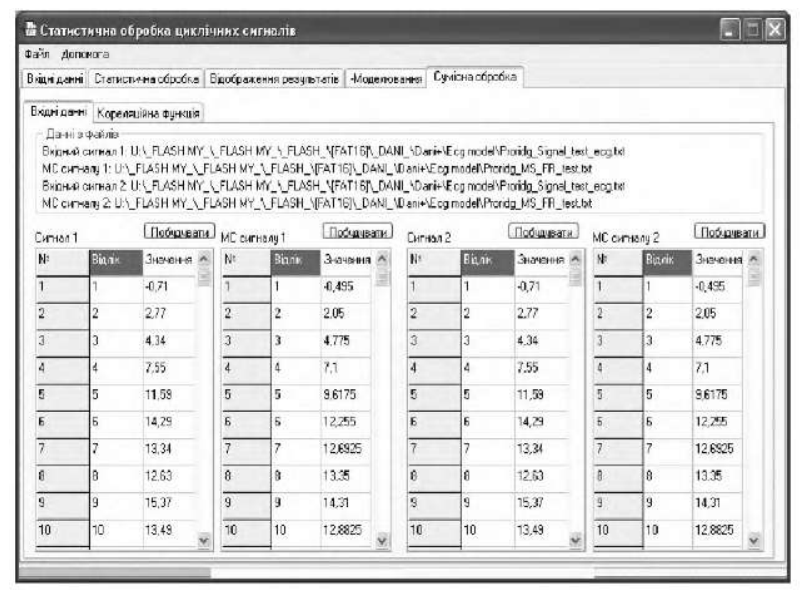

a кореляційна функція, отримана 3 врахуванням функції ритму.

Приклад інтерфейсу програми вводу синхронно зареєстрованих даних (а) та їх сумісної обробки (б) наведено на рисунку 6.

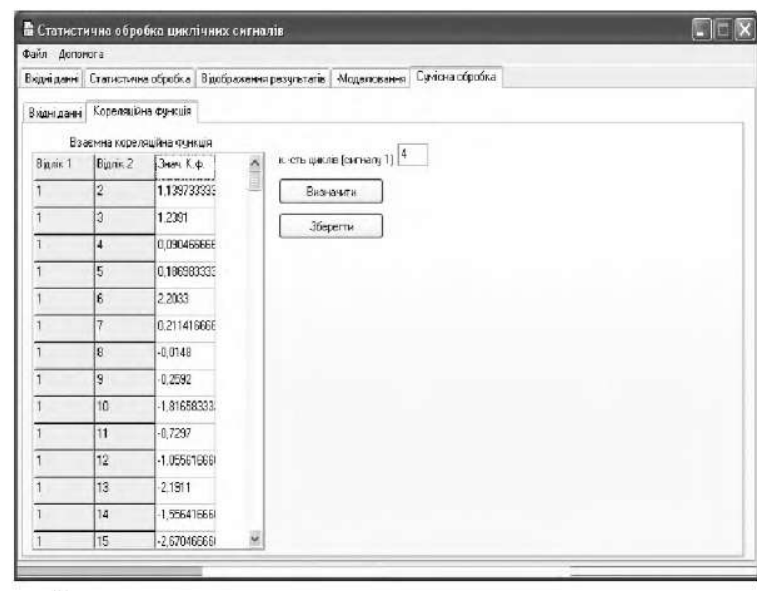

6

Puc. 6. Загальний вигляд інтерфейсу програми вводу синхронно зареєстрованих біосигналів (а) та їх сумісної обробки (б).

Висновки. Розроблений комплекс програм дозволяє проводити статистичну обробку СЗБС в поліграфах і отримувати оцінки математичного сподівання, дисперсії, автокореляційної та сумісної кореляційної функцій (з врахуванням функції ритму та з врахуванням періоду). Даний програмний комплекс може бути використаний як складова частина сучасних поліграфів з метою підвищення достовірності та повноти обстеження на поліграфі, внаслідок сумісної статистичної обробки СЗБС та використання однотипних діагностичних ознак для різних класів досліджуваних сигналів.

\section{Література}

1. Сверстюк А. С. Огляд поліграфів та методів обробки психофізіологічної інформації/А. С. Сверстюк//Медична інформатика та інженерія. - 2011. - № 2. - С. 44-48.

2. Pavlidis I. Thermal image analysis for polygraph testing / I. Pavlidis, J. Levine // Engineering in Medicine and Biology Magazine - Vol. 21, Issue 6. - P. 56-64. 
3. Li Jiang. A novel approach to analyze the result of polygraph / Li Jiang, Zhuo Qing, Wang Wenyuan // Systems, Man, and Cybernetics, Nashville, TN 2000 - International Conference on Volume:4 - P. 2884-2886.

4. Лупенко С. А. Математичне моделювання сигналів серця в задачах технічної кардіометрії на базі їх моделі у вигляді циклічного випадкового процесу / С. А. Лупенко, Ю. Студена // Вісник Тернопільського державного технічного університету. - 2006. - Т. 11, №1. - С. 134-142.

5. Лупенко С. А. Циклічне функціональне відношення як основа математичного формалізму теорії моделювання та аналізу циклічних сигналів 1С. А. Лупенко // Вісник Тернопільського державного технічного університету. - 2007. - T. 12, №3. - C. 183-195.
6. Лупенко С. А. Статистичний сумісний аналіз біосигналів на основі вектора циклічних ритмічно пов'язаних випадкових процесів / С. А. Лупенко, Я. В. Литвиненко, А. С. Сверстюк//Електроніка та системи управління (Національний авіаційний університет). - 2008. - №4 ( 18 ) . С. 22-29.

7. Сверстюк А. С. Статистичні методи обробки синхронно зареєстрованих кардіосигналів / А. С. Сверстюк // Медична інформатика та інженерія. - 2008. - № 2. - С. 5457.

8. Литвиненко Я. В. Програмний комплекс для обробки та моделювання синхронно зареєстрованих кардіосигналів 3 використанням моделей та методів теорії циклічних функціональних відношень / Я. В. Литвиненко, С. А. Лупенко, А. С. Сверстюк // Вісник Хмельницького національного університету. - 2009. - № 5. - С. 80-87. 